\title{
Design of piston bowl geometry for better combustion in direct-injection compression ignition engine
}

\author{
PRABHAKARA RAO GANJI*, RUDRA NATH SINGH, V R K RAJU and S SRINIVASA RAO \\ Department of Mechanical Engineering, National Institute of Technology, Warangal 506 004, India \\ e-mail: ganjiprabhakar@gmail.com
}

MS received 2 September 2016; revised 17 March 2017; accepted 7 September 2017; published online 7 June 2018

\begin{abstract}
The current computational fluid dynamics (CFD) study presents the effect of piston bowl geometry on the performance and emissions of a direct-injection diesel engine. Different piston bowl profiles, namely, hemispherical combustion chamber (HCC), shallow depth combustion chamber (SCC) and toroidal combustion chamber (TCC), have been created with a baseline compression ratio of 17.5. CONVERGE ${ }^{\mathrm{TM}}$ CFD code coupled with the SAGE combustion model was used for numerical analysis. It is observed that the TCC piston bowl geometry renders better air-fuel mixture inside the cylinder, which leads to a homogeneous charge. Further, numerical experiments are carried out to analyze suitable TCC piston bowl geometry by varying the depth of the bowl. Out of all the cases, the case with $1.26 \mathrm{~mm}$ decrease in depth of bowl from the baseline (TCC) design gives better emissions and performance characteristics.
\end{abstract}

Keywords. CI engine; combustion; emissions; piston bowl geometry.

\section{Introduction}

Internal combustion (IC) engines are widely used in modern day across the world. Owing to stringent pollution norms, most of the researchers have been exploring for better engine designs with minimum emissions. Two most important concerns in diesel-fuelled CI engine are NOx and soot emissions [1,2]. The improvement of air and fuel mixture will improve combustion engine performance. There are many ways to improve the air-fuel mixture inside a cylinder, and changing piston bowl geometry is one of them. Several researchers have worked on combustion chamber and different types of piston bowl geometry [3].

The combustion of air and fuel mixture and emission formation in diesel engine show very close relationship with piston bowl geometry [4]. Experimental studies on the effects of different bowl geometries of diesel engines were represented by Jaichandar and Annamalai [5]. In their study, three bowl geometries, namely hemispherical combustion chamber (HCC), toroidal combustion chamber (TCC) and shallow-depth combustion chamber (SCC), were tested with diesel and biodiesel fuels. These three piston bowl geometries were compared and observed. Reduction in CO, unburned hydrocarbons (UHCs) and soot but $\mathrm{NO}_{\mathrm{x}}$ emission were slightly higher in TCC as compared to HCC and TCC. The brake thermal efficiency of TCC piston bowl geometry was higher than that of HCC and SCC piston bowl geometries. A simulation study [6] reveals

*For correspondence that piston bowl geometry affects the combustion and performance characteristics of direct-injection (DI) CI engines. Further, these studies have been used to optimise the piston bowl geometry and spray angle in order to improve the performance and reduce the emissions.

The flow of gas inside a cylinder is controlled by swirl and turbulent kinetic energy. Optimised piston bowl geometry along with swirl ratio is modeled to reduce fuel consumption and emissions [7]. Piston bowl geometry plays an important role in the motion of air and fuel inside the cylinder. A high swirl ratio developed from piston geometry may produce better air-fuel mixture [8]. Park et al [9] studied the dimethyl ether (DME) engine and optimised engine combustion chamber for different operating conditions. Five different types of combustion chamber geometry were analyzed, and it was reported that deeper cup piston bowl geometry is best for reducing $\mathrm{NOx}$, soot, $\mathrm{HC}$ and $\mathrm{CO}$ emissions. Beard et al [10] discussed different types of piston bowl geometries used, such as flat and W shaped. It was observed that a piston bowl can enhance the mixing rate of air and fuel and can control the turbulence level. A small change in the piston bowl geometry has an effect on the swirl ratio and turbulence intensity. The $\mathrm{W}$-shaped bowl produces more swirl and turbulence at top dead centre (TDC) position as compared to flat piston bowl geometry. Prasad et al [11] studied three-dimensional CFD simulations for flow of air-fuel mixture and swirl in re-entrant combustion chamber. Several geometries were identified which had produced high swirl ratio and high turbulent kinetic energy (TKE), but very few piston bowl designs were 
identified for smaller engines. Payri et al [12] created five different types of piston bowl geometries and the results were validated with CFD analyses. Piston bowl radius was observed to play a lead role for flow of fuel near TDC. CFD analysis has the potential to design equipment with higher performance and fewer emissions. Song et al [13] analyzed seven different piston bowl shapes. Squish and swirl were found to play a very important role in turbulence generation in a diesel engine. The model was analyzed by coupling swirl, squish, turbulence and piston bowl shape for better combustion. Raj et al [14] conducted numerical analysis on piston bowl geometry using STAR-CD CFD software. Four different configurations of a piston bowl, such as flat, inclined, centre bowl and inclined offset bowl, were analyzed. Centre bowl geometry was seen to perform better than other bowl shapes because it produces high swirl and TKE. These parameters play a major role in engine performance and emissions reduction. In the present study, the effect of three basic types of piston bowls such as HCC, SCC and TCC was investigated for performance and emissions. The better design of these basic types was further analyzed by varying the bowl depth.

\section{Numerical simulation and methodology}

The present study used CONVERGE ${ }^{\mathrm{TM}}$ [15] simulation software for CFD analysis for different piston bowl geometries. CONVERGE automatically generates a

Table 1. Key Sub models used in the CFD analysis.

\begin{tabular}{|c|c|}
\hline Bore $(\mathrm{mm})$ & 87.5 \\
\hline Stroke $(\mathrm{mm})$ & 110 \\
\hline Connecting rod length (mm) & 243 \\
\hline $\begin{array}{l}\text { Maximum injection pressure } \\
\text { (bar) }\end{array}$ & 280 \\
\hline Speed (R.P.M) & 1500 \\
\hline Rated power $(\mathrm{kW})$ & 3.5 \\
\hline $\begin{array}{l}\text { Injected mass of fuel } \\
(\mathrm{kg} / \mathrm{cycle})\end{array}$ & $2.57778 \mathrm{e}-05$ \\
\hline Compression ratio & 17.5 \\
\hline Start of injection/ (aTDC) & $-23^{\circ}$ \\
\hline Injection duration (CAD) & $22^{\circ}$ \\
\hline Load \% & 100 \\
\hline \multirow[t]{2}{*}{ Inlet valve timings } & IVO $-184.5^{\circ} \mathrm{aTDC}$ \\
\hline & IVC $-144.5^{\circ} \mathrm{aTDC}$ \\
\hline \multirow[t]{2}{*}{ Exhaust valve timings } & EVO $144.5^{\circ} \mathrm{aTDC}$ \\
\hline & EVC $184.5^{\circ} \mathrm{aTDC}$ \\
\hline Piston temperature $(\mathrm{K})$ & 523 \\
\hline Cylinder temperature (K) & 443 \\
\hline Head temperature $(\mathrm{K})$ & 523 \\
\hline Fuel injection system & $\begin{array}{c}\text { Direct injection by multi-hole } \\
\text { nozzle }\end{array}$ \\
\hline No of nozzle holes & 3 \\
\hline Nozzle hole diameter & $0.255 \mathrm{~mm}$ \\
\hline Injection pressure (Max) & 280 bar \\
\hline
\end{tabular}

perfectly orthogonal structured grid at runtime using adaptive mesh refinement (AMR) based on simple, user-defined grid control parameters. This grid generation method completely eliminates the need to manually generate a grid. Combustion process can be considered as chemical and thermal processes that are dependent on each other. SAGE [16] model has been incorporated into CONVERGE, which helps in including the detailed chemistry in combustion applications with a set of chemkin format input files. Chalmers mechanism [17] is used for combustion chemistry of n-heptane and NOx formation, which consists of 42 species and 168 reactions. N-heptane is chosen because its $\mathrm{H} / \mathrm{C}$ ratio is very close to that of diesel. The various submodels used in the present CFD analysis are listed in table 1. Different input and boundary conditions used for setting up the simulations are listed in table 2. These boundary and initial conditions remain the same for all the cases. In order to compare the results, boundary conditions are kept constant for all the cases. All the initial conditions of the simulation are taken at the inlet valve closing (IVC). The geometry of the three piston bowl shapes are described in figure 1. The computational domain of HCC, SCC and TCC used for the present simulation is shown in figure 2.

\subsection{SAGE detailed chemical kinetics model}

In order to include detailed chemistry in combustion applications, the SAGE model [16] has been incorporated into CONVERGE. This approach allows the user to employ detailed chemical kinetics in combustion simulations with a set of CHEMKIN formatted input files, which are considered the standard format for defining chemical mechanisms in this study. The SAGE model uses the CVODES solver (which solves initial value problems for ordinary differential equation (ODE) systems), which is part of the SUNDIALS [26] (SUite of Nonlinear and DIfferential/ ALgebraic equation Solvers) package. SUNDIALS is also a

Table 2. Specifications of variable compression ratio (VCR) engine.

\begin{tabular}{|c|c|}
\hline Turbulence model & RNG $k-\varepsilon[18]$ \\
\hline Injection drop distribution & $\begin{array}{l}\chi^{2}(\text { chi squared }) \\
\text { distribution [15] }\end{array}$ \\
\hline Drop drag & Dynamic drag model [19] \\
\hline Droplet collision model & NTC model [20] \\
\hline Collision outcomes model & $\begin{array}{l}\text { Post collision outcomes } \\
\text { [21] }\end{array}$ \\
\hline Drop turbulent dispersion & O'Rourke model [22] \\
\hline Drop/wall interaction & Rebound/slide model [23] \\
\hline Evaporation model & $\begin{array}{c}\text { Chiang drop correlations } \\
\text { [24] }\end{array}$ \\
\hline Spray breakup & KH-RT [25] \\
\hline $\begin{array}{l}\text { Combustion modeling and chemical } \\
\text { reaction mechanism }\end{array}$ & $\begin{array}{c}\text { SAGE [16] and Chalmers } \\
\text { Mechanism [17] }\end{array}$ \\
\hline
\end{tabular}



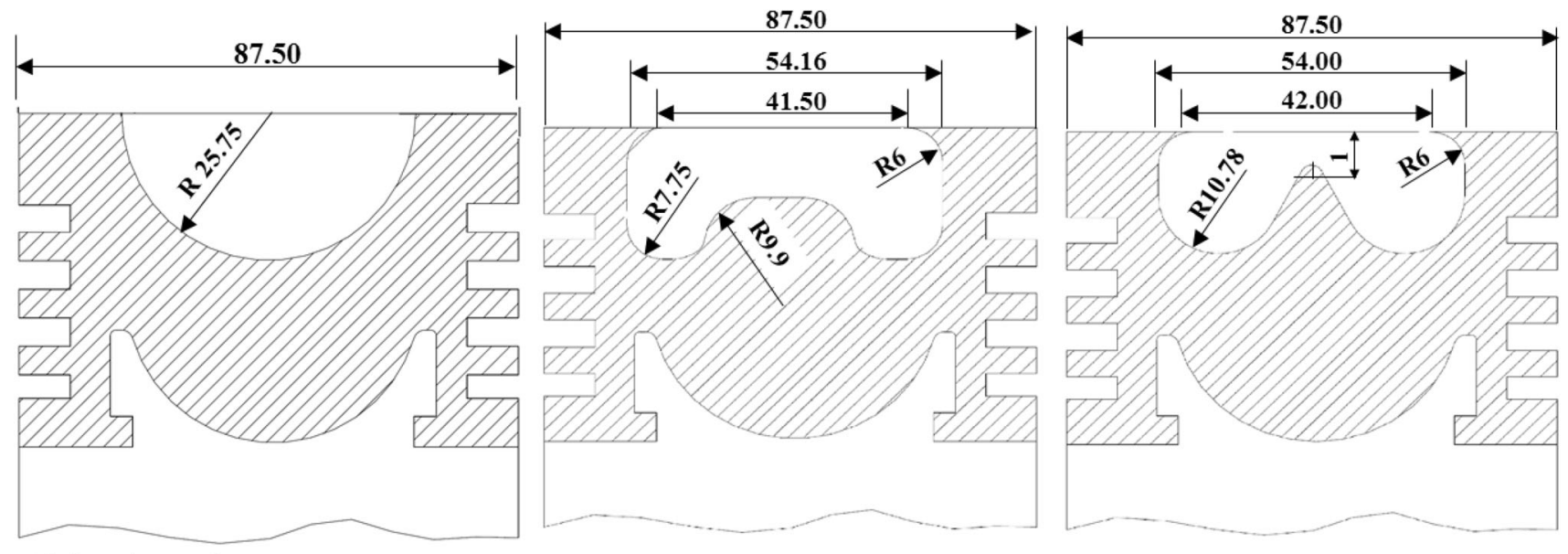

All dimensions are in $\mathrm{mm}$

Figure 1. Geometry of the three basic designs HCC, SCC and TCC [5].

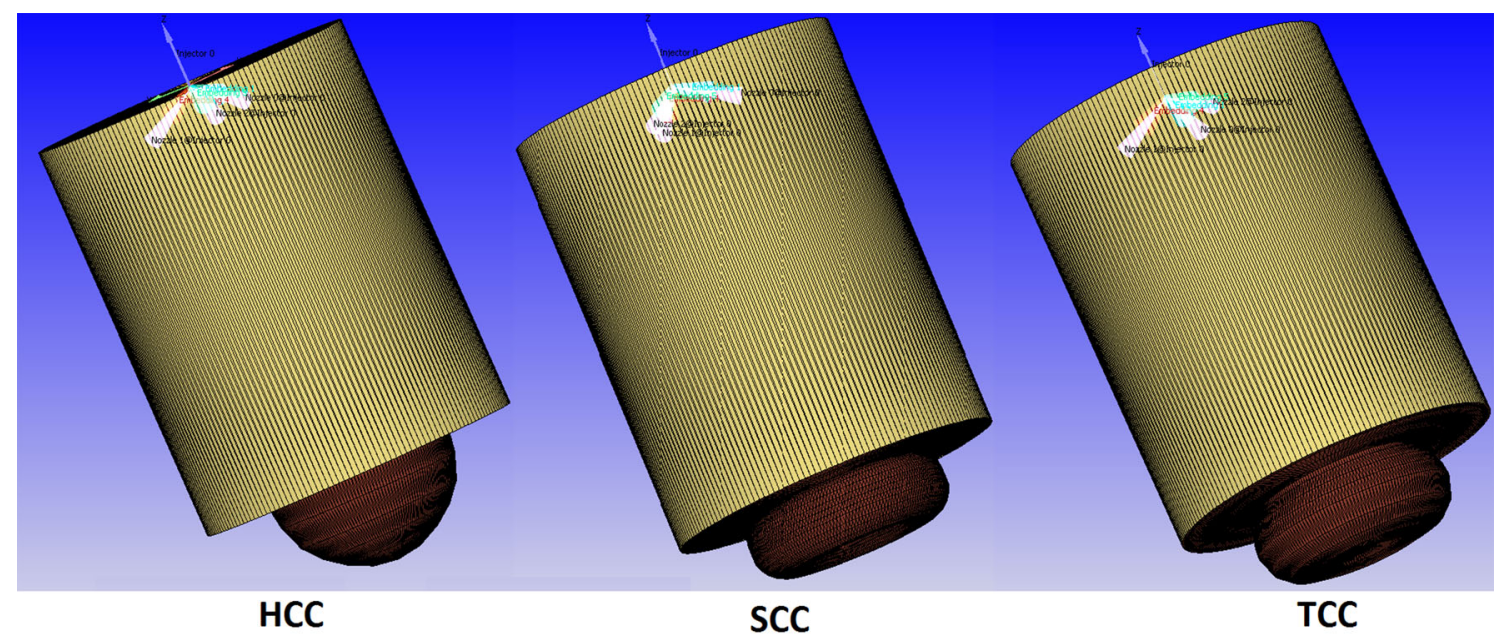

Figure 2. Grid generated computational domain of the HCC, SCC and TCC.

part of CONVERGE. The detailed chemistry solver, SAGE, calculates the reaction rates for each elementary reaction, while the CFD solves the transport equations. SAGE, along with an accurate mechanism, can be used for modeling many combustion regimes (ignition, premixed, mixing controlled).

\subsection{Experimental set-up}

Experiments were carried out using four-stroke, singlecylinder, direct-injection, water-cooled VCR engine test rig (shown in figure 3) which is naturally aspirated. AVL 444 exhaust gas analyzer is used to measure the $\mathrm{NO}_{\mathrm{x}}$ emissions and AVL 437C smoke meter is used to measure the smoke. The engine is coupled to eddy current dynamometer for loading. The in-cylinder pressure is calculated using piezoelectric transducer. The technical specifications of the engine are listed in table 2. The engine is equipped with a fuel injector nozzle with three holes which pressurises the fuel and injects at a maximum pressure of $280 \mathrm{bar}$. The fuel injector is mounted centrally over the piston crown. The engine operates at a constant speed of $1500 \mathrm{rpm}$. The engine has a hemispherical combustion chamber (HCC) with overhead valve arrangements. Diesel fuel is used for both experimental and numerical work.

\section{Model validation}

The simulation and experiment results are compared to validate numerical results obtained from CFD code CONVERGE. The predicted numerical results were validated by comparing the pressure variation with the crank angle of HCC bowl geometry with that of the experiment conducted 


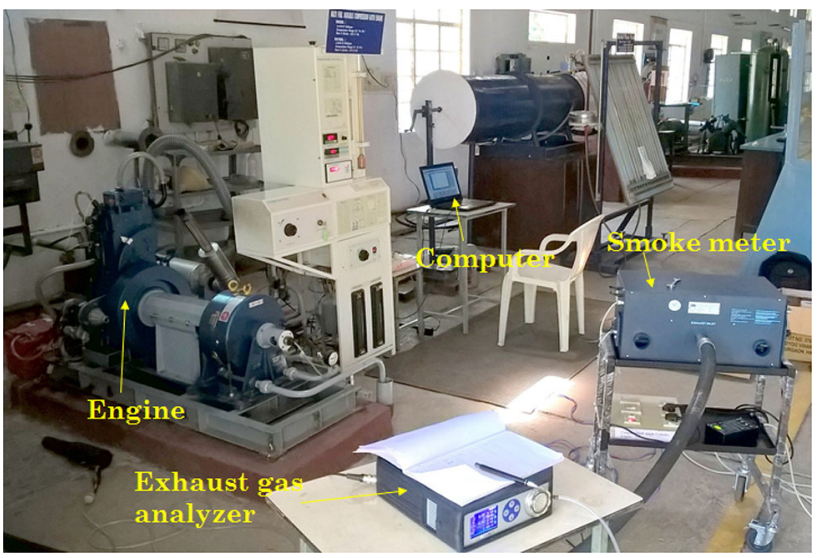

Figure 3. Experimental setup of VCR engine.

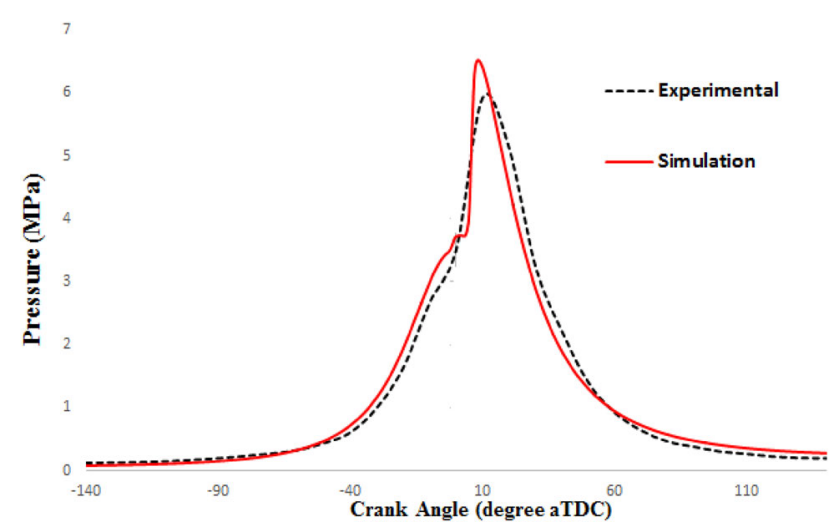

Figure 4. Validation of pressure vs crank angle for HCC case.

at $100 \%$ load condition. Figure 4 shows the variation of pressure with crank angle. The trends of simulation are similar to that of the experiment. However, a slight difference of about $6.2 \%$ in peak pressure is observed. Experimental pressure is lesser as compared to simulation, perhaps because during the compression stroke the gases may escape from the crevice region and would end up with lower in-cylinder pressure. Comparison of emissions is also shown in table 3 . The difference between numerical and experimental results for soot and $\mathrm{NO}_{\mathrm{x}}$ is observed to be $5 \%$ and $6 \%$, respectively.

\section{Results and discussions}

After successfully validating the simulation model with the experimental results, three different piston bowl shapes, namely, HCC, SCC and TCC, were selected to evaluate the present problem. Based on the performance and emissions, a better design is chosen to analyze further to optimise for the performance and emissions.
Table 3. Comparison of emissions for HCC baseline.

\begin{tabular}{lcc}
\hline & Experimental & Simulation \\
\hline Soot $(\mathrm{g} / \mathrm{kWh})$ & 1.38 & 1.46 \\
NOx $(\mathrm{g} / \mathrm{kWh})$ & 4.48 & 4.27 \\
\hline
\end{tabular}

\subsection{Comparison of HCC, SCC and TCC bowl shapes}

Figure 5 shows the comparison of pressure variation with crank angle for the three piston bowl geometries. The variation shows that the peak pressure of TCC bowl geometry is higher than that of as compared to the other two piston bowl geometries due to better combustion in TCC by virtue of better mixture formation of air and fuel. This may be due to improved swirl motion of air in the combustion chamber, which in turn leads to better combustion [27]. Figure 6 shows that NOx variation is high in TCC bowl geometry than in other cases due to its high incylinder pressure, which causes an increase in temperature within the combustion chamber. Figure 7 shows that soot emission is low in TCC bowl geometry than in the other cases. Though there is substantial decrease in soot, a penalty in $\mathrm{NO}_{\mathrm{x}}$ is observed for the TCC. Similar trends are also in good agreement with Jaichandar and Annamalai [5]. Based on the present numerical analysis and also from the literature support [5], it was evident that out of these three shapes, TCC is a better option in terms of indicated specific fuel consumption (ISFC) and soot. However, an increment in NOx emissions has been observed. So there is a need for further improvement of TCC geometry for simultaneous reduction of $\mathrm{NO}_{\mathrm{x}}$ and soot emissions without compromising the engine performance.

4.1 a Analysis of TCC piston geometry: The primary goal of this study is to find a suitable shape and size of combustion chamber (bowl) for better combustion. In this regard, the depth of the bowl (shown in figure 8) has been varied for five different cases in such a way that the compression ratio is maintained constant (17.5). The corresponding dimension for the depth of bowl of five different combinations is given in table 4. All the five cases are compared with TCC base line on the basis of their performance and emission characteristics. Variation of in-cylinder pressure with crank angle is shown in figure 9. It can be observed that the peak pressure of the base line configuration is highest compared to all other five cases and case 4 has the lowest. However, when the ISFC is compared (from figure 10), ISFC for case 3 is at par with the TCC base line, which means that the indicated power in case 3 and baseline is almost same, but a higher peak pressure is observed for the baseline. Similarly, the in-cylinder temperature variation with respect to crank angle is shown in figure 11 . The peak in-cylinder temperature of TCC base line is found 


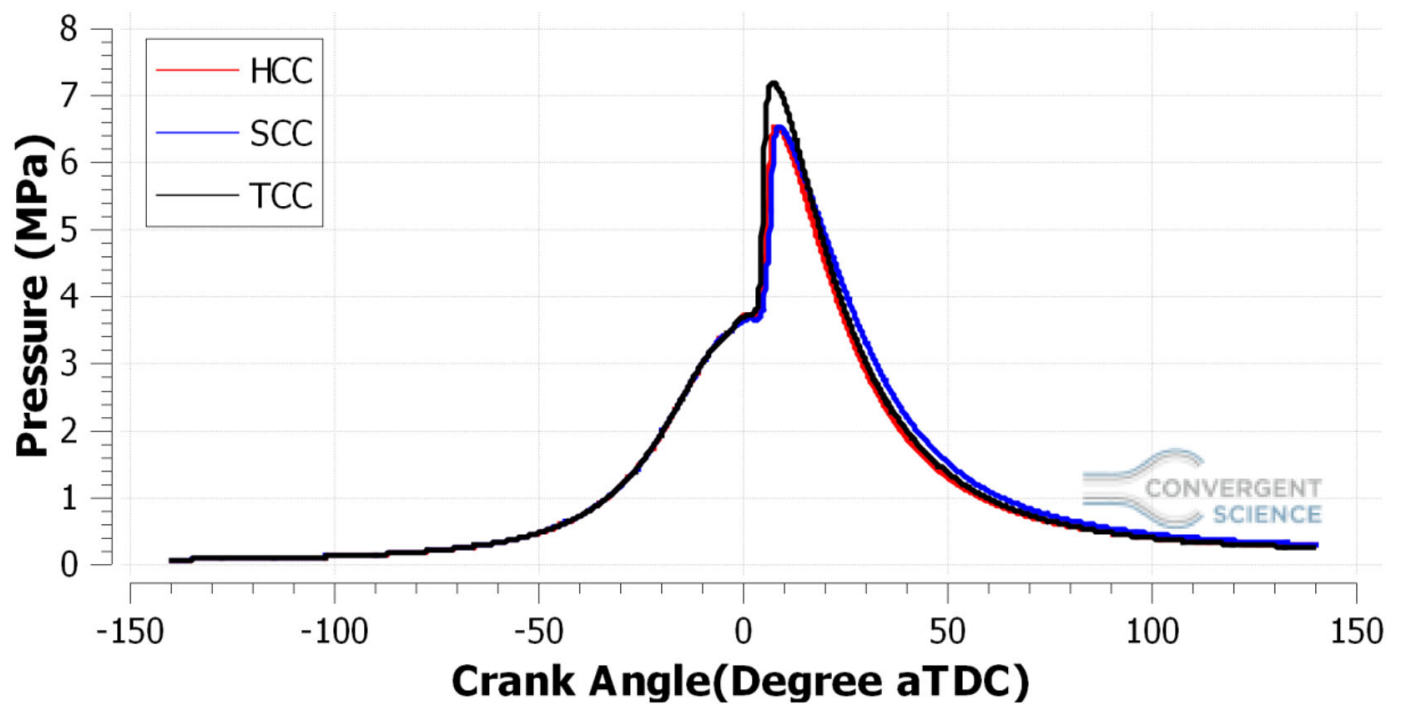

Figure 5. Comparison of pressure vs crank angle between HCC, SCC and TCC.

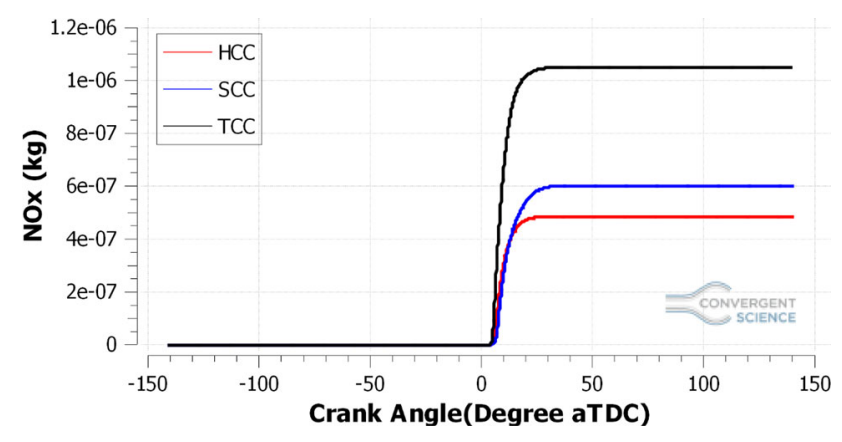

Figure 6. Comparison of $\mathrm{NO}_{\mathrm{x}}$ vs crank angle between $\mathrm{HCC}$, SCC and TCC.

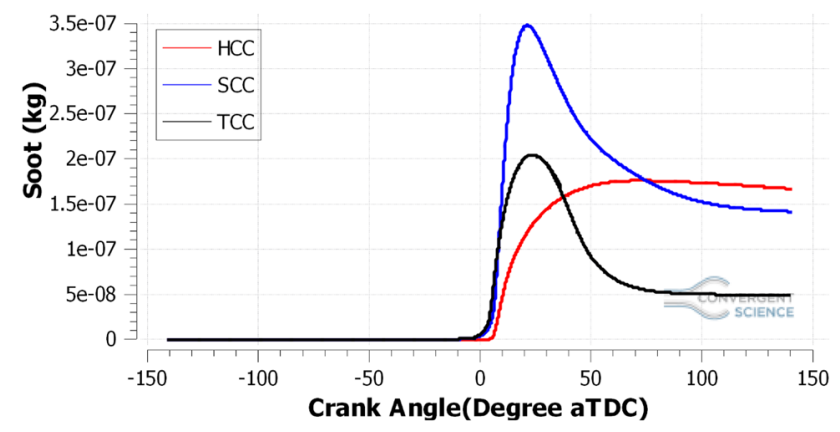

Figure 7. Comparison of Soot vs crank angle between HCC, SCC and TCC.

to be the highest than in other geometries, whereas case 1 has the lowest.

Figure 12 shows variation of swirl ratios for different bowl configurations. It is observed that peak swirl ratio is attained at the time of combustion (around TDC) for all the configurations, which means the swirl is intensified when

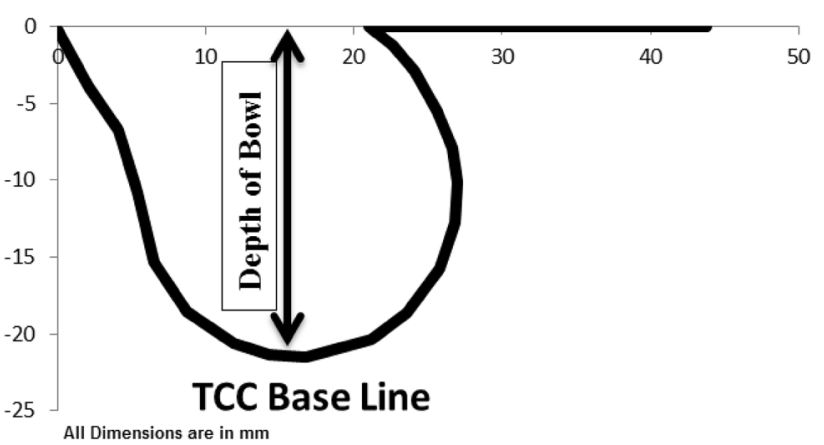

Figure 8. Representation of TCC bowl geometry (one half).

Table 4. Depth of bowl for different cases.

\begin{tabular}{lc}
\hline & Depth of bowl in mm \\
\hline TCC (Base line) & 21.56 \\
Case 1 & 22.50 \\
Case 2 & 23.46 \\
Case 3 & 20.30 \\
Case 4 & 19.24 \\
Case 5 & 23.58 \\
\hline
\end{tabular}

the piston reaches TDC as the radius of rotation reduces. It is also observed that the peak swirl ratio is highest for case 1 and lowest for case 5 .

In figure $13, \mathrm{NO}_{\mathrm{x}}$ variation is shown for different cases. It is observed that all the modified geometries have lesser NOx emissions than the baseline case. However, it is observed that in cases 3 and 4 (depth of bowl decreased) NOx reduces drastically compared to other cases (depth of 


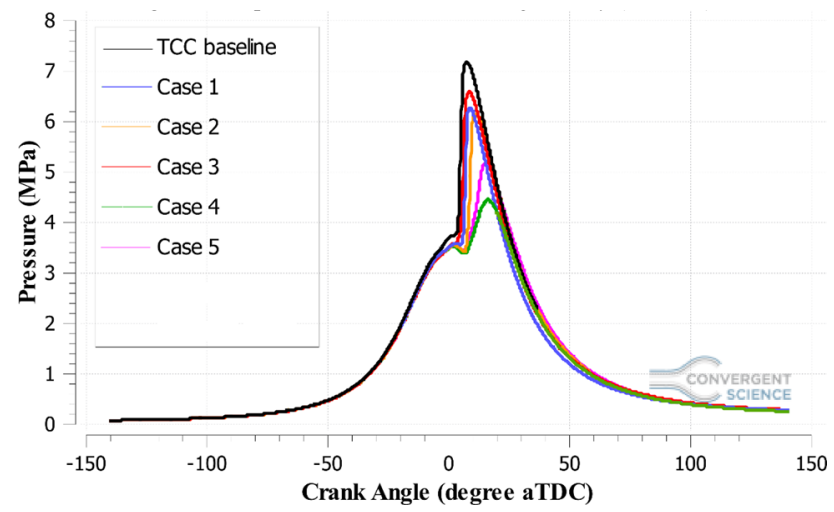

Figure 9. Pressure variation with crank angle for different cases.

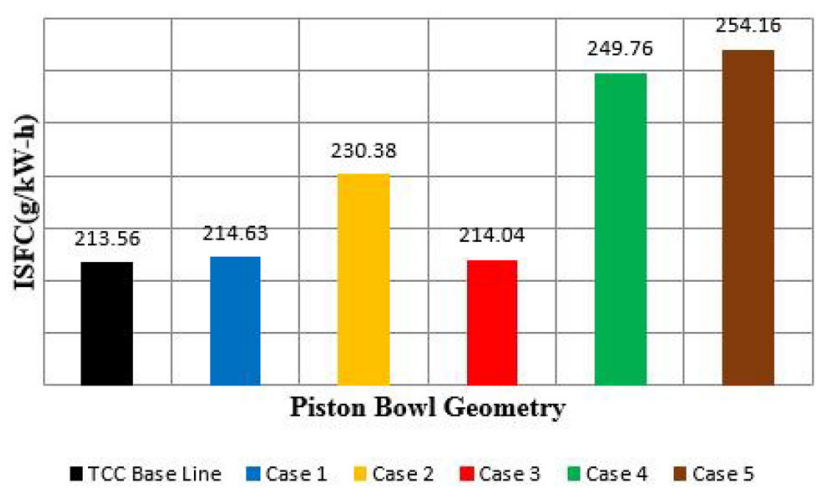

Figure 10. Comparison of ISFC for different bowl configurations.

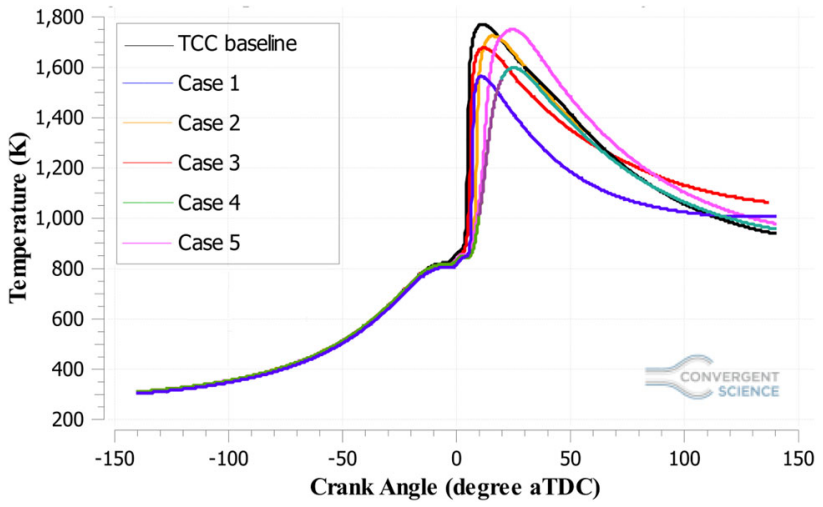

Figure 11. Temperature variation with crank angle for different cases.

bowl increased). In diesel engines, the NOx formation is highly active at higher temperatures. The lesser combustion temperatures for cases 3 and 4 (observed from figure 11) reduce the $\mathrm{NO}_{\mathrm{x}}$ formation.

Figure 14 shows that soot emissions are highest for case 5 (lowest swirl ratio) and lowest for case 3 corresponding to SR 3.75, because, when the depth of bowl is reduced, the soot is reduced because of a better homogeneous mixture

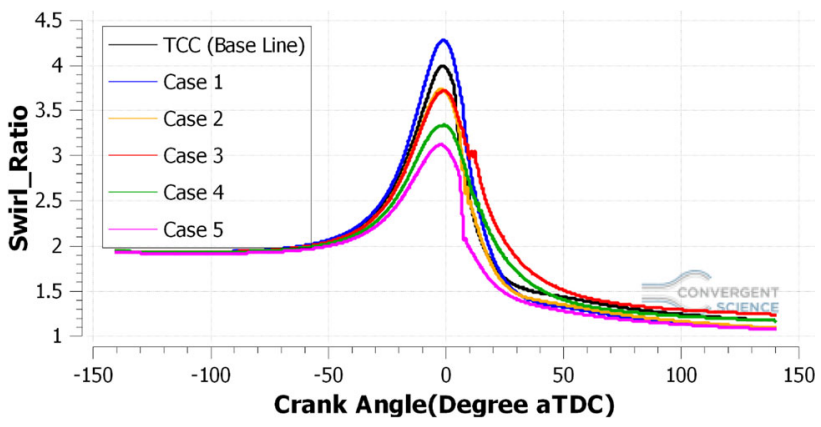

Figure 12. Swirl ratio variation with crank angle for different cases.

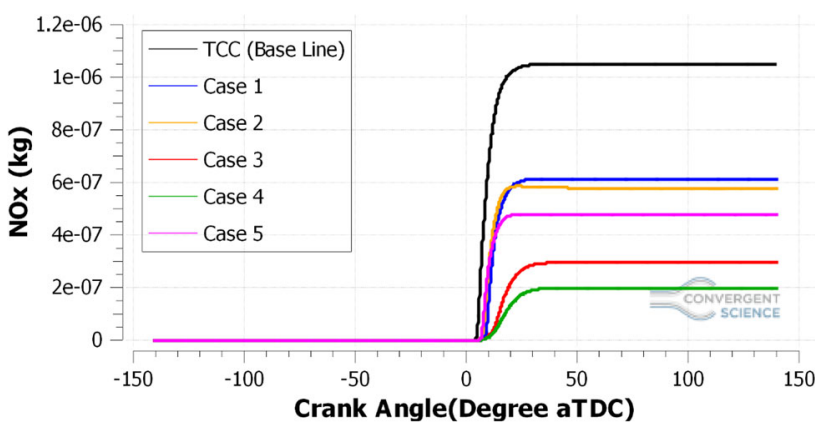

Figure 13. $\mathrm{NO}_{\mathrm{x}}$ emission for different cases.

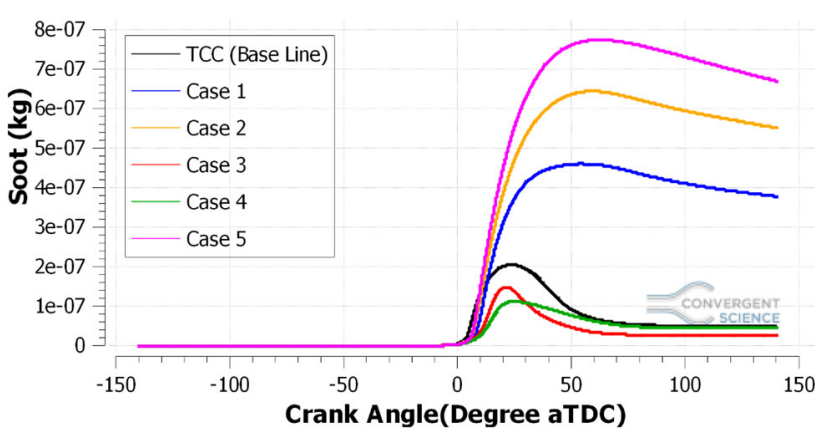

Figure 14. Soot emission at different cases.

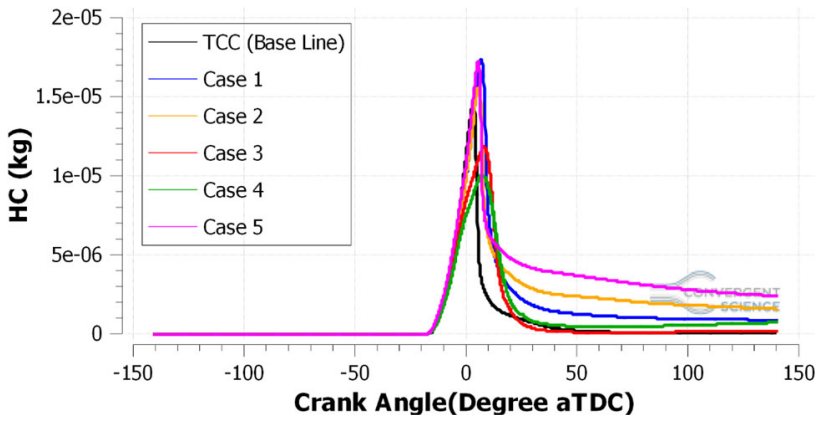

Figure 15. HC emission at different cases. 


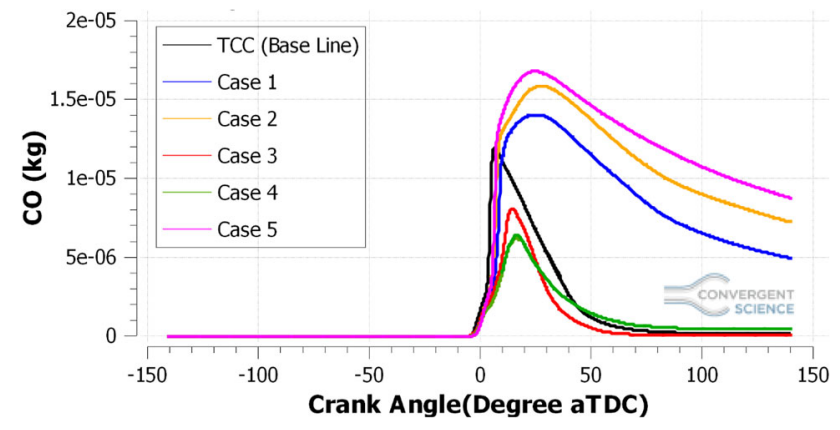

Figure 16. $\mathrm{CO}$ emission at different cases.

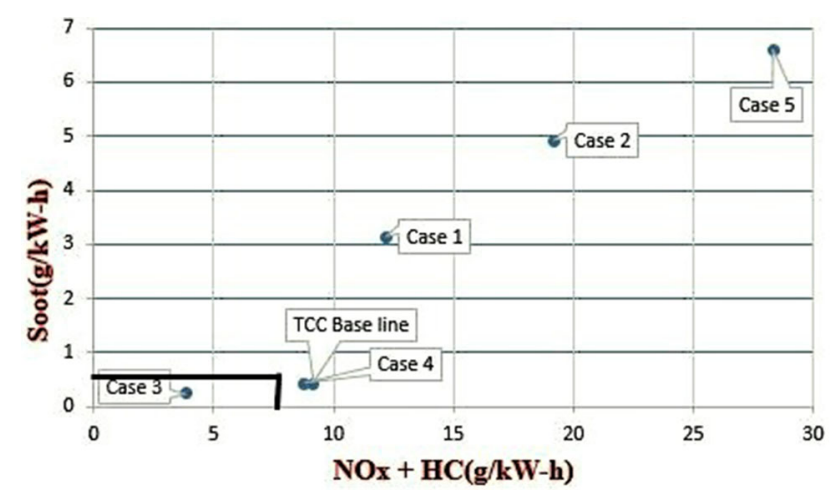

Figure 17. Soot $\mathrm{Vs} \mathrm{NO}_{\mathrm{X}}+\mathrm{HC}(\mathrm{g} / \mathrm{kW}-\mathrm{h})$.

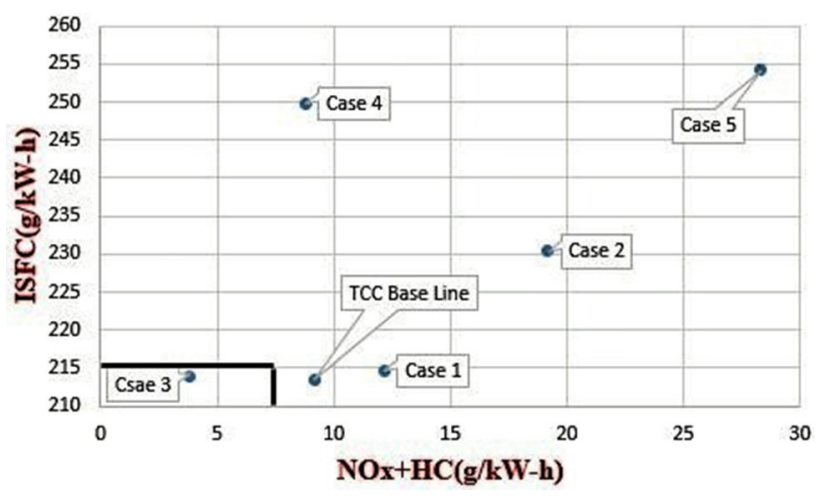

Figure 18. ISFC Vs $\mathrm{NO}_{\mathrm{x}}+\mathrm{HC}(\mathrm{g} / \mathrm{kW}-\mathrm{h})$.

attained by the higher swirl generation for case 3 (see figure 20). Though case 1 has the highest swirl ratio, it fails to generate the lesser soot SR $(>4.25)$. We can also ensure that the threshold value of the SR for this engine configuration is around 3.75 .

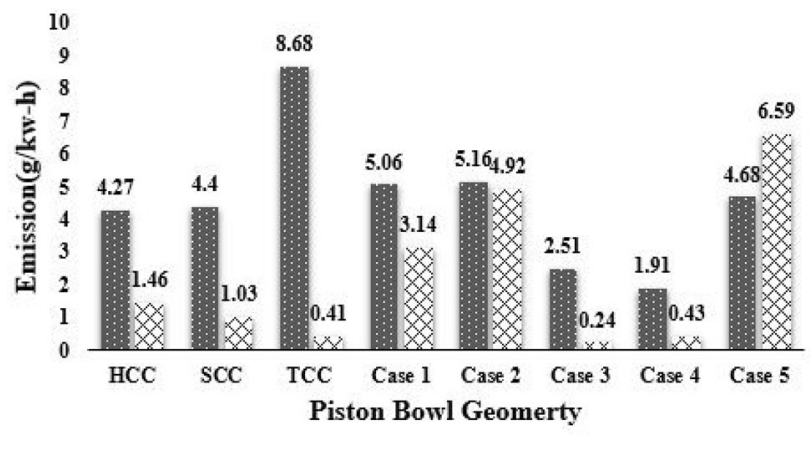

NOx $\times$ Soot

Figure 19. Soot and $\mathrm{NO}_{\mathrm{x}}$ for different piston bowl geometries.

Variation of $\mathrm{HC}$ and $\mathrm{CO}$ for different piston bowl configurations is shown in figures 15 and 16, respectively. Similar trends have been observed for both the pollutants. These pollutants mainly get oxidised when the post-combustion temperatures are above $1000 \mathrm{~K}$ [28]. It is also observed due to the higher swirl ratios $(>4.25)$ may be imputed to the extensive lean region of the spray and poor oxidation reactions, so cases 1,2 and 5 bowl shapes have the higher formation of $\mathrm{HC}$ and $\mathrm{CO}$.

\section{Selection of piston bowl geometry}

After analyzing the results for all the five cases of piston bowl geometry, a better design of emissions and ISFC is decided by using the BS norms [29] (Bharat Stage emission standards). Figure 17 shows the values of soot and NOx along with $\mathrm{HC}$ for all five cases. It is found that case 3 falls within the range of acceptance as decided by the BS norms $[0.3(\mathrm{~g} / \mathrm{kWh})$ for soot emission and $7.5(\mathrm{~g} / \mathrm{kWh})$ for NOx + $\mathrm{HC}$ emission]. Figure 18 shows the values of ISFC and NOx along with HC for all the five cases. Case 3 is in the acceptable range $[215(\mathrm{~g} / \mathrm{kWh})$ for ISFC and $7.5(\mathrm{~g} / \mathrm{kWh})$ for $\mathrm{NOx}+\mathrm{HC}$ emission]. Case 3 produces less amount of NOx and soot emission as compared to all other cases including HCC, SCC and TCC base line, which can be observed from figure 19. Soot emission is reduced by $41.46 \%$ and NOx emission is reduced by $71.08 \%$ for case 3 as compared to TCC base line bowl geometry. Figure 20 shows the contours, mean and variance of the equivalence ratio for the TCC baseline and case 3. It can be observed from the figure that the variance of equivalence ratio for the optimum case (case 3) is lesser than that for TCC baseline. This is evident that case 3 has more homogeneous distribution of equivalence ratio as compared to TCC baseline. 


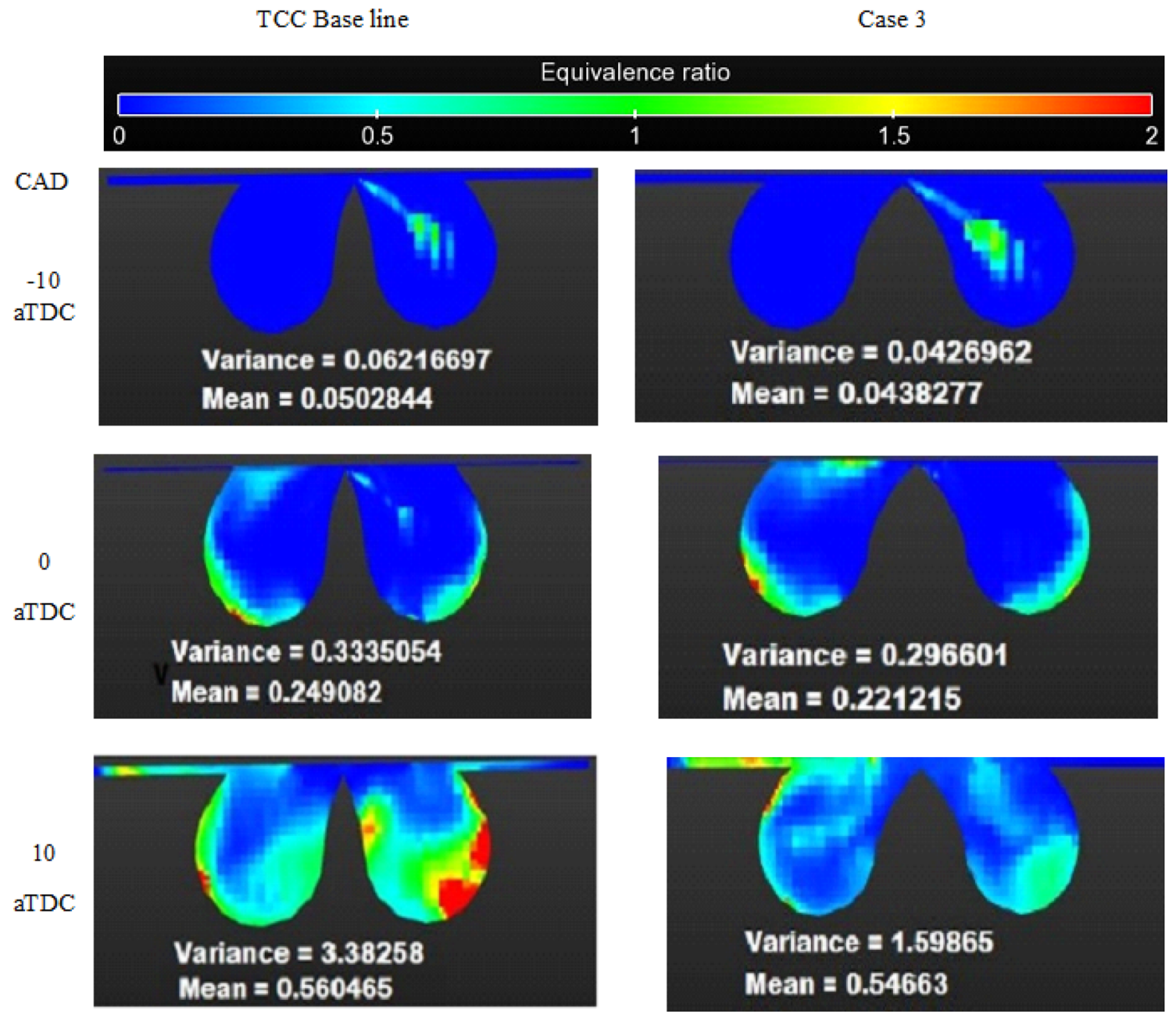

Figure 20. Equivalence ratio distribution for TCC baseline and case 3 .

\section{Conclusions}

In the present CFD study, the effect of different piston bowl geometries at constant speed and load were analyzed using CONVERGE $^{\mathrm{TM}}$ CFD software. Early results show that TCC piston bowl shape is found to be the better among the three shapes in terms of ISFC and soot but resulted in higher NOx emissions. The analysis was extended to evaluate the performance and emission characteristics of TCC bowl shape for five other cases. The cases have been compared and the optimum was chosen based on the lower emissions (NOx and soot). Increase in depth of bowl from TCC baseline from 21.56 to $23.46 \mathrm{~mm}$ increases the swirl ratio and helps in mixture homogeneity and further increase in depth of bowl ruins the combustion characteristics. Decrease in depth of bowl from TCC baseline (21.56 to 20.30) improves the combustion, and further reduction in depth of bowl leads to deterioration in performance. In the present study, swirl ratio of around 4 favors the combustion characteristics for the given engine configuration. Homogeneity of the charge inside the cylinder was improved for case 3 and thereby reduces the soot emissions. Case 3 was found to be the best among all the cases with lower NOx and soot also its ISFC is at par with the TCC baseline. The depth of bowl $20.30 \mathrm{~mm}$ (Case 3) of the TCC shape is found to be the optimum, and the corresponding NOx and soot emissions are lower by $71 \%$ and $41 \%$, respectively, as compared to TCC baseline.

\section{Acknowledgements}

This work was supported by Centre of Excellence (COE), Centre for Sustainable Energy Studies of Technical Education Quality Improvement Programme (TEQIP-II), India.

\section{Nomenclature}

ATDC after top dead center

bTDC before top dead center

CAD crank angle degree

CFD computational fluid dynamics

CO carbon monoxide 
UHC unburned hydrocarbon

HCC hemispherical combustion chamber

HRR heat release rate

NOx nitrogen oxides

PM particulate matter

SCC shallow depth combustion chamber

TCC toroidal combustion chamber

\section{References}

[1] Kumar S and Chauhan M K 2013 Numerical modeling of compression ignition engine: a review. Renew. Sust. Energy. Rev. 19: 517-530

[2] Shi Y, Ge H W and Reitz R D 2011 Computational optimization of internal combustion engines. Springer Science \& Business Media, Berlin

[3] Gafoor C A and Gupta R 2015 Numerical investigation of piston bowl geometry and swirl ratio on emission from diesel engines. Energy Convers. Manag. 101: 541-551

[4] Li J, Yang W M, An H, Maghbouli A and Chou S K 2014 Effects of piston bowl geometry on combustion and emission characteristics of biodiesel fueled diesel engines. Fuel 120: 66-73

[5] Jaichandar S and Annamalai K 2012 Influences of re-entrant combustion chamber geometry on the performance of Pongamia biodiesel in a DI diesel engine. Energy 44(1): 633-640

[6] Lim J and Min K 2005 The effects of spray angle and piston bowl shape on diesel engine soot emissions using 3-D CFD simulation (No. 2005-01-2117). In: SAE Technical Paper

[7] Saito T, Daisho Y, Uchida N and Ikeya N 1986 Effects of combustion chamber geometry on diesel combustion (No. 861186). In: SAE Technical Paper

[8] Fuchs T R and Rutland C J 1998 Intake flow effects on combustion and emissions in a diesel engine (No. 980508). In: SAE Technical Paper

[9] Park S 2012 Optimization of combustion chamber geometry and engine operating conditions for compression ignition engines fueled with dimethyl ether. Fuel 97: 61-71

[10] Béard P, Mokaddem K and Baritaud T 1998 Measurement and modeling of the flow-field in a DI diesel engine: effects of piston bowl shape and engine speed (No. 982587). In: SAE Technical Paper

[11] Prasad B V V S U, Sharma C S, Anand T N C and Ravikrishna R V 2011 High swirl-inducing piston bowls in small diesel engines for emission reduction. Appl. Energy 88(7): 2355-2367

[12] Payri F, Benajes J, Margot X and Gil A 2004 CFD modeling of the in-cylinder flow in direct-injection diesel engines. Comput. Fluids 33(8): 995-1021
[13] Song J, Yao C, Liu Y and Jiang Z 2008 Investigation on flow field in simplified piston bowls for DI diesel engine. Eng. Appl. Comp. Fluid 2(3): 354-365

[14] Raj A R G S, Mallikarjuna J M and Ganesan V 2013 Energy efficient piston configuration for effective air motion-a CFD study. Appl. Energy 102: 347-354

[15] Richards K J, Senecal P K and Pomraning E 2014 CONVERGE (Version 2.2. O) Manual. Middleton, WI: Convergent Science, Inc

[16] Senecal P K, Pomraning E, Richards K J, Briggs T E, Choi C Y, McDavid R M and Patterson M A 2003 Multi-dimensional modeling of direct-injection diesel spray liquid length and flame lift-off length using CFD and parallel detailed chemistry (No. 2003-01-1043). SAE Technical Paper

[17] http://www.tfd.chalmers.se/ valeri/MECH.html

[18] Han Z and Reitz R D 1995 Turbulence modeling of internal combustion engines using RNG $\kappa-\varepsilon$ models. Combust. Sci. Technol. 106(4-6): 267-295

[19] Liu A B, Mather D and Reitz R D 1993 Modeling the effects of drop drag and breakup on fuel sprays. In: SAE Paper No. 930072

[20] Schmidt D P and Rutland C J 2000 A new droplet collision algorithm. J. Comput. Phys. 164(1): 62-80

[21] Post S L and Abraham J 2002 Modeling the outcome of drop-drop collisions in diesel sprays. Int. J. Multiph. Flow 28(6): 997-1019

[22] O'Rourke P J 1981 Collective drop effects on vaporizing liquid sprays (No. LA-9069-T). New Mexico, NM: Los Alamos National Lab

[23] Gonzalez D M A, Lian Z W and Reitz R D 1992 Modeling diesel engine spray vaporization and combustion. SAE Trans. 101(3): 1064-1076

[24] Chiang C H, Raju M S and Sirignano W A 1992 Numerical analysis of convecting, vaporizing fuel droplet with variable properties. Int. J. Heat Mass Transfer 355: 1307-1324

[25] Beale J C and Reitz R D 1999 Modeling spray atomization with the Kelvin-Helmholtz/Rayleigh-Taylor hybrid model. Atomiz. Sprays 9(6): 623-650

[26] Hindmarsh A C, Brown P N, Grant K E, Lee S L, Serban R, Shumaker D E and Woodward C S 2005 SUNDIALS: suite of nonlinear and differential/algebraic equation solvers. $A C M$ Trans. Math. Softw. (TOMS) 31(3): 363-396

[27] Henein N A, Bhattacharyya A, Schipper J, Kastury A and Bryzik W 2006 Effect of injection pressure and swirl motion on diesel engine-out emissions in conventional and advanced combustion regimes (No. 2006-01-0076). In: SAE Technical Paper

[28] Potter M, Durrett R and Motors G 2006 August Design for compression ignition high-efficiency clean combustion engines. In: 12th Annual Diesel Engine Emissions Reduction (DEER) conference

[29] https://www.dieselnet.com//standards/in/genset.php 